\title{
AS ELITES POLÍTICAS DE MARINGÁ: UM ESTUDO SOBRE A CÂMARA MUNICIPAL, 1997-2012
}

\section{Tiago Valenciano Previatto Amaral ${ }^{1}$}

Resumo: A presente pesquisa busca responder a seguinte questão: qual o caminho percorrido para que os vereadores de Maringá, da $11^{\mathrm{a}}$ à $14^{\mathrm{a}}$ Legislaturas, integrem a elite política local? A análise foi realizada a partir da relação existente entre a "Teoria das Elites" e o perfil dos parlamentares que exerceram mandato durante tais legislaturas, por intermédio do método posicional. Quanto à análise destes perfis, investigamos os padrões de recrutamento dos vereadores, como a origem familiar, o perfil sócio-profissional, a escolaridade, a trajetória política e os vínculos políticos, para apontarmos, assim, uma radiografia da Câmara Municipal de Maringá

Palavras-chave: Eleições; Câmara Municipal; Elites políticas; Maringá.

Resumen: Esta investigación busca responder la siguiente pregunta: ¿cuál es el camino a los consejeros de Maringa, del $11^{\mathrm{a}}$ al $14^{\mathrm{a}}$ Legislatura,para integrar la élite política local? El análisis se basó en la relación entre la "teoría de las élites" y el perfil de las legislaturas parlamentarias ejercido durante dicho plazo, a través del método de posición. El análisis de estos perfiles, se investigan los patrones de reclutamiento del Consejo, tales como antecedentes familiares, el socio-profesional, la historia de la educación, política y relaciones políticas, al señalar, además, una radiografía de la ayuntamiento del Maringá.

Palabras-clave: Concejales; Ayuntamiento; Élites políticas; Maringá.

Abstract: This research seeks to answer the question: what is the path to the councilors of Maringá, the 11 th to 14 th Legislature, to integratelocal political elite? The analysis was performed based on therelationship between the "Theory of the Elites" and the profile of parliamentary legislatures exercised during such term, through the positional method. The analysis of these profiles, we investigate the recruitment patterns of the council, such as family background, the socioprofessional, educational, political trajectory and the political, to point, so a radiograph of the City Hall of Maringá.

Key-words: City councillors; City Hall; Political elites; Maringá.

\footnotetext{
${ }^{1}$ Mestre em Ciências Sociais pela Universidade Estadual de Maringá (UEM). Atualmente, é Professor da
} Faculdade Alvorada, em Maringá-PR. 


\section{INTRODUÇÃO}

O objetivo deste trabalho é verificar quais são os atributos mais relevantes no recrutamento da elite legislativa de Maringá, isto é, partindo do pressuposto de que os vereadores posicionalmente compõem a elite política local, questionamos: quem são os componentes desta elite? Para tal, apresentaremos adiante o referencial teórico adotado, a justificativa do período escolhido, como foi desenvolvida a pesquisa e os resultados alcançados.

Optamos pela Teoria das Elites por analisar a política de um modo diferenciado das abordagens presentes em outros trabalhos sobre a política local ${ }^{2}$, ou seja, escolhemos pensar a política local enquanto um espaço no qual a minoria organizada pode comandar politicamente a maioria desorganizada e desarticulada. Portanto, esta concepção prevê que um grupo minoritário de lideranças irá comandar os negócios políticos de uma comunidade, por exemplo, definindo o futuro da mesma. Igualmente, convém destacar a utilização do método posicional para a realização da pesquisa, o qual privilegia a posição estratégica ocupada na sociedade por tais vereadores.

Considerando o espaço temporal dos trabalhos existentes e o estudo da Teoria das Elites, elegemos as quatro últimas legislaturas da Câmara Municipal de Maringá: $11^{\mathrm{a}}$ (de 1997 a 2000); $12^{\mathrm{a}}$ (de 2001 a 2004); $13^{\mathrm{a}}$ (de 2005 a 2008) e $14^{\mathrm{a}}$ (de 2009 a 2012). O critério para escolha dessas legislaturas foi o número de vereadores que compõem cada uma, levando em conta as recentes alterações nos legislativos municipais do Brasil. Assim, optamos pelas duas últimas legislaturas com 21 vereadores $\left(11^{\mathrm{a}}\right.$ e $12^{\mathrm{a}}$.) e as duas com 15 parlamentares $\left(13^{\mathrm{a}}\right.$ e $14^{\mathrm{a}}$.), pois a partir de 2013 novamente haverá alteração no total de vereadores em Maringá.

Quanto ao recrutamento político, destacamos sua utilização nas pesquisas que buscam identificar como foram selecionados os membros de uma determinada elite política. Pesquisar recrutamento político é, então, evidenciar e analisar o perfil político, social e econômico dos eleitos, isto é, daqueles que compõem uma elite escolhida pela população. Assim, a presente pesquisa procura entender quais são os atributos que a elite política possui e quais foram os impactos destes no decorrer da disputa pela obtenção do mandato. Abordaremos cinco fatores inerentes à formação de um perfil dos parlamentares pesquisados, segundo os pressupostos do recrutamento político elencados: a origem familiar, o perfil sócio-profissional e de classe; o grau de escolaridade; a trajetória política; e os vínculos institucionais.

${ }^{2}$ Como por exemplo, os trabalhos de Dias (2008), Tonella (1991) e Dias e Tonella (1999). 


\section{A RADIOGRAFIA DA CÂMARA MUNICIPAL DE MARINGÁ (1997-2012)}

Para delinearmos o perfil da Câmara Municipal de Maringá no período estudado, elegemos todos aqueles que obtiveram mandato, isto é, das 72 cadeiras disponíveis, 57 foram ocupadas e 15 foram preenchidas por vereadores reeleitos, ou seja, que já possuíam algum mandato e não foram inclusos nesta soma. Tal fato demonstra que aproximadamente $66 \%$ da quantidade de cadeiras foram preenchidas por novos vereadores3, ou seja, as alterações na composição da Câmara Municipal de Maringá no período analisado evidenciam as mudanças ocorridas. Portanto, podemos afirmar que houve grande movimentação de vereadores nestes 14 anos no parlamento maringaense, com alta incidência de novos personagens no cenário político local.

\subsection{Escolaridade}

A questão proposta quanto à escolaridade dos vereadores diz respeito às variáveis elite política versus alta escolaridade. Haveria a confirmação da hipótese "elite política é altamente escolarizada" no caso destes parlamentares? Verificamos que, dos vereadores que obtiveram mandato nas quatro legislaturas envolvidas na pesquisa, $54,5 \%$ possuem ensino superior completo. Acrescido àqueles que ainda cursam o ensino superior ou acabaram por não concluir o mesmo, o percentual eleva-se para $66,7 \%$, ou seja, dois terços dos 57 parlamentares já frequentaram cursos universitários. Somados aos que concluíram o ensino médio, atingimos 89,6\% dos vereadores, números que nos permitem apontar que a Câmara Municipal de Maringá nesse período pode ser caracterizada como um legislativo de alta escolaridade por duas vias: considerando os que já cursaram ou cursam um ensino superior ou os que ao menos encerram os estudos médios, como podemos verificar na tabela abaixo:

Tabela 1 Escolaridade dos vereadores de Maringá (1997-2012)

\begin{tabular}{l|c|c}
\hline Grau de Escolaridade & Quantidade de Vereadores & Porcentual \\
\hline Superior Completo & 31 & 54,5 \\
\hline Superior Incompleto & 07 & 12,2 \\
\hline Ensino Médio & 13 & 22,9 \\
\hline Ensino Médio Incompleto & 03 & 5,2 \\
\hline Ensino Fundamental & 03 & 5,2 \\
\hline Total & $\mathbf{5 7}$ & $\mathbf{1 0 0 \%}$ \\
\hline
\end{tabular}

Fonte: banco de dados do autor

3 Exceto os suplentes, totalizando assim 48 vereadores para 72 vagas. 
Quanto à hipótese de que há algum curso superior ou técnico que favorece o ingresso na carreira política, salientamos a predominância dos que cursam ou são formados em direito, com 21,1\% dos vereadores, seguido pelos médicos, com seis vereadores. Se considerarmos os cursos por grupo profissional, oito estão ligados à área de saúde (Medicina, Farmácia e Odontologia), número que ainda não supera a quantidade de bacharéis em direito - indicando uma inclinação da atividade legislativa relacionada ao direito.

Tabela 2 Cursos superiores e/ou técnicos realizados pelos vereadores de Maringá (1997-2012)

\begin{tabular}{l|c|c}
\hline Curso & Quantidade de vereadores & Porcentual \\
\hline Direito & $\mathbf{1 2}$ & $\mathbf{2 1 , 1}$ \\
\hline Medicina & 06 & 10,6 \\
\hline Outros & 04 & 7,0 \\
\hline Administração & 03 & 5,2 \\
\hline Pedagogia & 03 & 5,2 \\
\hline Comunicação & 02 & 3,5 \\
\hline Serviço Social & 02 & 3,5 \\
\hline Farmácia & 01 & 1,7 \\
\hline Matemática & 01 & 1,7 \\
\hline Economia & 01 & 1,7 \\
\hline Ciências Contábeis & 01 & 1,7 \\
\hline Filosofia & 01 & 1,7 \\
\hline Odontologia & 01 & 1,7 \\
\hline Teologia & 01 & 32,0 \\
\hline Sem formação & $\mathbf{0 1}$ & $\mathbf{1 0 0 \%}$ \\
\hline Total & $\mathbf{5 7}$ & \\
\hline
\end{tabular}

Fonte: banco de dados do autor

Se não considerarmos as quatro legislaturas envolvidas no período como um bloco homogêneo, mas as analisarmos em separado, constatamos que a $11^{\mathrm{a}}$ Legislatura, de 1997 a 2000, é a com maior grau de instrução, com mais de 70\% dos parlamentares possuindo grau superior, uma tendência que caiu nas legislaturas subsequentes mantendo-se nos últimos oito anos. Todavia, o número de vereadores com grau superior incompleto (tanto os que não concluíram o curso quanto os estudantes), cresceu desde 1997, ampliando a quantidade de parlamentares com curso superior.

Tais dados sobre a formação educacional dos vereadores da Câmara Municipal de Maringá nos permitem afirmar que o índice de escolaridade é alto, uma vez que cerca de dois terços do parlamento local possui ensino superior completo, tendência esta crescente ao longo dos anos. Esses dados corroboram com a afirmação de Codato e Gouvêa (2007), de que 89\% dos Deputados Estaduais de 1995 a 2002 possuíam o ensino superior completo. Logo, o parlamento maringaense - ainda que abaixo dos índices estaduais, reflete a alta escolarização da elite política legislativa e confirma a "vocação" dos formados em direito para o exercício da atividade parlamentar. 


\subsection{Origem familiar}

Em relação à origem familiar dos vereadores pesquisados, verificamos que apenas seis parlamentares possuem algum grau de parentesco no cenário político local - são os casos de Belino Bravin Filho, Maria Arlene de Lima, Marco Antonio Almendra Meger, Ulisses de Jesus Maia Kotsifas, Mário Sergio Verri e Evandro Buquera de Oliveira Freitas Júnior. Para isto, realizamos um levantamento histórico-familiar simples, no intuito de identificar se houve algum Vereador, Prefeito, Deputado Estadual ou Deputado Federal membro das famílias dos 57 parlamentares do período.

Deste modo, constatamos que a origem familiar não é um fator preponderante para a obtenção de um mandato como vereador em Maringá - perfazendo 10,5\% do total de parlamentares, e tampouco há presença da dominação tradicional segundo Max Weber (COHN, 2005). Logo, possuir algum membro na família no cenário da política local é uma condição que não favorece os postulantes para o cargo neste período analisado, o que implica dizer ainda que, por esse dado, fica difícil constatar a presença de "oligarquias" na política maringaense.

\subsection{Vínculos sociais e institucionais}

Apesar da não incidência de "oligarquias" na elite política local, questionamos: qual a importância dos vínculos sociais e o pertencimento às instituições pelos vereadores quanto à obtenção de mandato e sua manutenção no cenário político? Considerando esta pergunta, realizamos um levantamento dos perfis de cada parlamentar, identificando a participação em entidades, instituições, movimentos religiosos, sociais, entre outros. Tal questão é pertinente para a pesquisa, pois mesmo que os vínculos estabelecidos pelos vereadores não ofereçam uma garantia da presença destes na elite política local, podemos cruzar esses dados com a origem social e a ocupação dos parlamentares, a fim de compreender os perfis políticos (individual e do grupo).

Levantamos, assim, os vínculos institucionais estabelecidos por cada parlamentar e elaboramos uma lista das principais entidades que estes participam ou participaram. Além das entidades, optamos por incluir na lista alguma característica peculiar do vereador quando comparada com as dos demais parlamentares, como por exemplo, um comércio que interfira diretamente enquanto condição para obter o mandato, participações artísticas, culturais, desportivas, entre outras.

Incluímos os vereadores em mais de uma categoria quanto àqueles que possuem mais de um vínculo. Em primeiro lugar, destacamos que mais de um terço dos 
vereadores pesquisados participam ou participaram de alguma entidade direcionada à prática da filantropia - ainda que pertencessem aos clubes de serviço, o objetivo destes é praticamente o mesmo. Em segundo lugar, há a predominância dos que possuem alguma identificação religiosa, isto é, aqueles que possuem participação ativa em pastorais, grupos ou que possuem funções destacadas nas igrejas. Todavia, se considerarmos que outros três vereadores detêm posição de destaque em clubes esportivos, o vínculo com o desporto assumiria o segundo lugar, com nove parlamentares.

Tabela 3 Incidência de vínculos institucionais dos vereadores de Maringá por grupo de vínculo (1997-2012)

\begin{tabular}{l|c|c}
\hline Tipo de vínculo & $\begin{array}{l}\text { Vínculos / } \\
\text { Vereadores }\end{array}$ & Porcentual \\
\hline Entidades e clubes de serviço & 14 & 27,1 \\
\hline Sindicatos e Associações classistas & 10 & 19,2 \\
\hline Identificação religiosa & 09 & 17,3 \\
\hline Clubes de futebol & 06 & 11,5 \\
\hline Instituições de ensino & 03 & 5,7 \\
\hline Clubes & 03 & 5,7 \\
\hline Conselhos municipais e associações de moradores & 02 & 3,9 \\
\hline Outros & 05 & 9,6 \\
\hline Total & $\mathbf{5 2}$ & $\mathbf{1 0 0 \%}$ \\
\hline
\end{tabular}

Fonte: banco de dados do autor

Podemos considerar que os vínculos institucionais dos vereadores de Maringá do período estudado são de médio para alto, pois 36 dos 57 vereadores possuem algum tipo de vínculo. Desses, a participação nas entidades assistenciais, nas associações classistas/sindicais e no campo religioso são as de maior evidência, caracterizando-os assim como integrantes da elite institucional da cidade, assumindo posicionamento de destaque nas instituições - na maioria das vezes em cargos de direção das mesmas.

Em vista dessa inserção social, questionamos: qual o impacto dos vínculos institucionais estabelecidos e o que significa a tríade entidades assistenciais / sindicatos e associações classistas / religiosidade liderar a vinculação social destes parlamentares? Segundo Mills (1968), o triunvirato do poder nos Estados Unidos perpassa pela política, forças armadas e economia, compondo assim as altas rodas da sociedade. Estas altas rodas são frequentadas por pessoas de base social e psicológicas parecidas e que possuem interesses em comum - no geral, para pertencer à elite é necessário atuar em mais de um campo. Nesta definição, Mills caracteriza a elite social como uma espécie de "igrejinha", isto é, com os membros unidos, coesos, partilhando de um interesse comum e participando dos mesmos espaços. 
Salientamos que para pertencer à elite, conforme Mills, não basta apenas atuar politicamente, ou seja, é preciso uma inserção social maior, estabelecendo vínculos institucionais além do campo político. Nesta medida, apontamos que os vereadores de Maringá do período possuem uma vinculação social média /alta e a participação destes nas instituições sociais permite dizer que estes buscam um posicionamento enquanto elite da sociedade - e não somente como elite política local. Outrossim, para pertencerem a esta condição de elite social, os parlamentares associaram-se preferencialmente em três modalidades: clubes de serviço e entidades sociais, voltados para o voluntariado e que angariam um capital social relevante enquanto membros da elite social; participação em grupos religiosos, fator importante em um universo ligado à religiosidade4; e sindicatos e associações classistas, espaços também voltados para a socialização.

Assim, importa dizer que, conforme demonstrado por Tonella (1991), tendo em vista que Maringá é uma cidade de ocupação recente, esses espaços (clubes de serviço e entidades assistenciais, grupos religiosos e sindicatos e associações) são pontos de agregação social de uma população majoritariamente migrante. Enfim, ter uma participação ativa nesses lugares gera visibilidade, o que é sempre um grande capital político.

\subsection{Trajetória política}

Para identificarmos a trajetória política dos vereadores, utilizamos três variáveis: 1) histórico político de cada vereador e, sobretudo, disputas prévias antes de assumir o primeiro mandato; 2) idades em que os parlamentares assumiram o primeiro mandato até o término do último; 3) e alternância partidária no período, identificando as mudanças partidárias dos parlamentares. Esses pontos ajudam-nos a delinear o perfil dos vereadores de Maringá de 1997 a 2010 e colaboram para elucidar algumas perguntas: há alguma trajetória específica para se tornar vereador na cidade? Existe uma faixa etária específica para se tornar vereador?

O levantamento do histórico político de cada vereador foi efetuado sob duas vertentes: antes de assumir o mandato e após a respectiva passagem pelo legislativo local. Diante da pequena quantidade de vereadores com alguma inserção política antes de se tornar vereador neste período, a carreira política prévia é pequena, uma vez que grande parte destas carreiras inicia-se após a vereança, isto é, para a maioria dos

\footnotetext{
4 Segundo dados do Observatório das Metrópoles, a composição populacional de Maringá segundo orientação religiosa divide-se em 73,72\% de católicos, $21,15 \%$ de evangélicos e 5,13\% de muçulmanos, budistas, espíritas, ateus e outros.

http://www.observatoriodasmetropoles.ufrj.br/como_anda/como_anda_RM_maringa.pdf Acesso em: o2 fevereiro 2011.
} 
vereadores este foi (ou é) o primeiro mandato, galgando novos postos posteriormente. Ainda assim, consideramos as disputas eleitorais prévias, verificando as eleições disputadas por cada vereador até a obtenção do primeiro mandato (e após o mesmo) desde 1982.

Se somarmos todas as eleições disputadas pelos vereadores de Maringá no período, o primeiro lugar se concentra naqueles que disputaram duas eleições ao menos, com 33,3\%, seguido por três disputas com 22,9\%. Salientamos que, a rigor, apenas oito parlamentares disputaram uma única eleição e se elegeram, retirando-se posteriormente do cenário político.

Tabela 4 Média de eleições disputadas pelos vereadores de Maringá (1997-2012)

\begin{tabular}{l|c|c}
\hline Eleições disputadas no total & Quantidade de vereadores & Porcentual \\
\hline Uma eleição & 08 & 14,0 \\
\hline Duas eleições & 19 & 33,3 \\
\hline Três eleições & 13 & 22,9 \\
\hline Quatro eleições & 05 & 8,8 \\
\hline Cinco eleições & 06 & 10,6 \\
\hline Seis eleições & 05 & 8,7 \\
\hline Sete eleições & 01 & 1,7 \\
\hline
\end{tabular}

Fonte: banco de dados do autor

Verificamos que após a obtenção de um mandato de vereador, há facilidade para permanência no cenário político - mas não em cargos eletivos ascendentes, como Deputado e Prefeito, por exemplo. Alguns dos vereadores pesquisados obtiveram sucesso nas eleições para Deputado Estadual e Deputado Federal, mas esta é uma tendência que não se manteve ao longo dos anos5. Dias e Tonella (1999) destacavam a eleição para a Câmara Municipal como primeiro passo de uma carreira política:

O Legislativo municipal tende a ser a esfera mais acessível para o cidadão aspirar a ser um representante popular. O exercício do mandato de vereador tanto propicia o amadurecimento quanto consolida e amplia a representatividade política. A partir dessa experiência, muitos aspiraram a realizar novos vôos políticos (DIAS \& TONELLA, 1999, p. 85).

\subsection{Faixa etária}

Sobre a faixa etária dos vereadores, elegemos a idade que o vereador possuía ao assumir o primeiro mandato e confrontamo-la com a idade ao término do último mandato obtido, isto é, no fim da passagem pela Câmara Municipal. Como

\footnotetext{
${ }^{5}$ Para Deputado Estadual são os casos de Divanir Braz Palma e Serafina Martins Carrilho (1998), Manoel Batista da Silva Júnior (2006 e 2010) e Evandro Buquera de Oliveira Freitas Júnior (2010); e para Deputado Federal Edmar de Souza Arruda (2010).
} 
pesquisamos um espaço de tempo delimitado, alguns vereadores obtiveram mandato antes do período escolhido e outros ainda poderão assumir um novo mandato após 2012. Neste caso, consideramos a idade do vereador na primeira legislatura assumida (ainda que não compreendesse o período entre 1997 e 2012) até a o último ano da última legislatura, mesmo que seja 2012.

A maioria dos vereadores permanecem na Câmara Municipal durante 4 anos (31 casos), seguidos de 13 parlamentares que ficaram por 8 anos, outros 6 por 12 anos, 3 por 20 anos, um por 18 anos e apenas um por 24 anos. Apesar da baixa permanência de tempo no legislativo municipal, obter um mandato de vereador significa ingressar no cenário político local, já que outros cargos são logo desempenhados - como apontado anteriormente.

A média etária entre os vereadores pesquisados para assumir o mandato figura entre os 41 e 50 anos e, ao final do mandato, entre os 51 e 60 anos. A tabela abaixo demonstra que, entre os 31 e 50 anos o vereador obtém o primeiro mandato e, entre os 41 e 60 anos encerra sua passagem pela Câmara Municipal, ou seja, na média inicia-se a carreira após os 31 anos e a termina após os 51 anos, demonstrando assim que os maringaenses optam por pessoas mais experientes para o cargo de vereador, mas sem que sejam de idade avançada.

Tabela 5 Média de idade dos vereadores de Maringá ao assumir o mandato e ao término (1997-2012)

\begin{tabular}{l|c|c|c|c}
\hline $\begin{array}{l}\text { Faixa } \\
\text { etária }\end{array}$ & $\begin{array}{l}\text { Vereadores - } \\
\text { início }\end{array}$ & Porcentual & $\begin{array}{l}\text { Vereadores - } \\
\text { fim }\end{array}$ & Porcentual \\
\hline $18-30$ & 4 & 7,0 & 2 & 3,5 \\
\hline $31-40$ & 14 & 24,6 & 6 & 10,5 \\
\hline $41-50$ & 22 & 38,6 & 17 & 29,9 \\
\hline $51-60$ & 12 & 21,1 & 19 & 33,4 \\
\hline $61-70$ & 3 & 5,2 & 11 & 19,2 \\
\hline Sem inf. & 2 & 3,5 & 2 & 3,5 \\
\hline Total & $\mathbf{5 7}$ & $\mathbf{1 0 0}$ & $\mathbf{5 7}$ & $\mathbf{1 0 0}$ \\
\hline
\end{tabular}

Fonte: banco de dados do autor

Assim, convém salientar que, em média, os vereadores de Maringá fizeram suas carreiras políticas em um prazo de vinte anos, com o ingresso na política por volta dos quarenta anos e término próximo aos sessenta anos. Este fator demonstra a opção do eleitorado local por um legislativo mais experiente quanto ao quesito "idade", épocas em que as relações sociais provavelmente ocorrem nos âmbitos demonstrados até então, como, por exemplo, a carreira profissional, os vínculos sociais e institucionais e o relacionamento estabelecido nesses espaços.

\subsection{Mudança partidária}


Por fim, analisamos a alternância partidária dos vereadores, no intuito de verificar quais foram às mudanças ocorridas durante os mandatos. Para tal, analisamos o grau de fidelidade partidária dos vereadores, a fim de mensurar se trocar ou permanecer no partido político é um indício de obter um mandato. Nesta variável, não consideramos os vereadores suplentes, mas somente as vagas em âmbito partidário até porque os suplentes não trocaram de partido durante os respectivos mandatos e, na maioria dos casos, mantiveram-se por curto período na Câmara Municipal.

Para tal, consideramos sempre a bancada da eleição, isto é, a agremiação na qual o vereador pertencia quando da disputa eleitoral, além de considerar a totalidade das setenta e duas vagas na Câmara de Vereadores - e não somente os 48 parlamentares que ocuparam as respectivas cadeiras. Logo, obedecemos ao critério das bancadas dos partidos políticos e não os vereadores que assumiram mandato ao longo do período.

Tabela 6 Vereadores por partido em Maringá, segundo bancada da eleição (1997-2012)

\begin{tabular}{l|c|c}
\hline Partido & Vereadores & Porcentual \\
\hline PSDB & 13 & 18,2 \\
\hline PP & 12 & 16,7 \\
\hline PT & 8 & 11,2 \\
\hline PMDB & 8 & 11,2 \\
\hline PTB & 8 & 11,2 \\
\hline DEM & 6 & 8,4 \\
\hline PDT & 4 & 5,6 \\
\hline PR & 3 & 4,2 \\
\hline PHS & 2 & 2,7 \\
\hline PRP & 2 & 2,7 \\
\hline PST & 2 & 2,7 \\
\hline PSD & 1 & 1,3 \\
\hline PMN & 1 & 1,3 \\
\hline PC do B & 1 & 1,3 \\
\hline PSB & 1 & 1,3 \\
\hline Total & $\mathbf{7 2}$ & $\mathbf{1 0 0}$ \\
\hline
\end{tabular}

Fonte: banco de dados do autor

As três siglas que obtiveram o maior número de vereadores no período - PSDB, PP e PT, também chefiaram a prefeitura municipal, ou seja, a tendência para as eleições legislativas espelha a disputa no executivo, pois o PSDB venceu em 1997, o PT em 2000 e o PP em 2004 e 2008. Do mesmo modo, o PTB (que cedeu o vice-prefeito em 1997) e o PDT (vice em 2004 e 2008) possuem destaque, com 8 e 4 cadeiras, respectivamente. Ainda em bom posicionamento no ranking de partidos, o PMDB preserva sua 
característica de maior vencedor em eleições para a vereança no Brasil, com 8 cadeiras e o DEM possui seis vereadores.

Quanto à movimentação partidária ocorrida no período, podemos caracterizá-la como moderada, reduzida a partir de 04 de outubro de 2007, após a regulamentação do Supremo Tribunal Federal quanto à fidelidade partidária. Segundo a nova lei, quem trocar de partido político a partir de 16 de março de 2007 sem justificativa cabível estará sujeito a um processo de expulsão da sigla. Tal instrumento surgiu no intuito de coibir as exacerbadas trocas partidárias. Adotamos as trocas partidárias ocorridas durante o exercício de mandatos no período pesquisado e, para os vereadores que obtiveram mandato antes de 1996, constamos também os partidos que estes fizeram/ fazem parte. As eventuais trocar partidárias após a passagem de um vereador pela Câmara Municipal (ainda que este assuma outro cargo por outro partido) não foram consideradas.

Tabela 7 Movimentação partidária dos vereadores de Maringá (1997-2012)

\begin{tabular}{c|c|c}
\hline $\begin{array}{c}\text { Quantidade de } \\
\text { Vereadores }\end{array}$ & $\begin{array}{c}\text { Trocas } \\
\text { partidárias }\end{array}$ & $\begin{array}{c}\text { Porcentual } \\
\text { (Vereadores) }\end{array}$ \\
\hline 02 & 03 & 5,2 \\
\hline 03 & 02 & 3,5 \\
\hline 13 & 01 & 22,9 \\
\hline 30 & o0 & 52,6 \\
\hline 09 & Suplentes & $\mathbf{1 5 , 8}$ \\
\hline $\mathbf{5 7}$ & - & $\mathbf{1 0 0 \%}$ \\
\hline
\end{tabular}

Fonte: banco de dados do autor

Assim, podemos apontar que os vereadores do período não efetuaram grande movimentação partidária, já que 52,6\% dos parlamentares não realizaram nenhuma troca de agremiação partidária. Portanto, há um alto índice na manutenção do quadro partidário-parlamentar no período, demonstrando que a permanência em um partido político é motivo de sucesso para obter uma cadeira na Câmara Municipal.

\subsection{Origem sócio-profissional}

Para delinear o perfil dos vereadores pesquisados quanto à origem sócioprofissional, três tarefas foram realizadas: 1) cruzar a formação profissional dos vereadores em relação à última profissão exercida antes de obter o primeiro mandato como vereador; 2) delimitar os grupos profissionais, a partir das profissões e ocupações exercidas por cada parlamentar; 3) especificar as atividades profissionais desempenhadas pelos vereadores. A partir destes critérios, traçamos o perfil sócio- 
profissional quanto à base de seleção das elites políticas (permeáveis ou impermeáveis, isto é, se são democráticas ou elitistas); cruzar a profissão com o comportamento político adotado, a fim de que se possa mensurar se a atividade profissional interfere na atividade política; e examinar se existe alguma profissão que combina ou facilita o exercício da vereança.

Se cruzarmos as variáveis ocupação e profissão, constatamos que $33 \%$ dos vereadores possuem ocupação diferente da profissão, isto é, exercem outra atividade daquela obtida em cursos superiores ou passaram a desempenhar a vereança sem obter profissão anterior. Em vista disso, podemos afirmar que a maioria dos vereadores de Maringá (66\%) no período continuou exercendo suas profissões ao longo do mandato, aliando assim a atividade profissional e o mandato como vereador, lado a lado.

Tabela 8 Profissões dos vereadores de Maringá segundo Grupo Profissional - classificação do autor (1997-2012)

\begin{tabular}{l|c|c}
\hline Grupo profissional & Quantidade de vereadores & Porcentual \\
\hline Professores & 07 & 12,3 \\
\hline Advogados & 07 & 12,3 \\
\hline Médicos & 06 & 10,5 \\
\hline Empresariado & 06 & 10,5 \\
\hline Funcionalismo público & 06 & 10,5 \\
\hline Meios de comunicação & 03 & 5,2 \\
\hline Comerciários & 03 & 5,2 \\
\hline Profissionais liberais & 03 & 5,2 \\
\hline Religiosos & 03 & 5,2 \\
\hline Assistência Social & 02 & 3,6 \\
\hline Outros & 11 & $\mathbf{1 9 , 5}$ \\
\hline Total & $\mathbf{5 7}$ & $\mathbf{1 0 0 \%}$ \\
\hline
\end{tabular}

Fonte: banco de dados do autor

Esmiuçando as classificações dos grupos profissionais, constatamos que os profissionais liberais ainda constituem o grupo majoritário profissional - todavia, com delimitação bem caracterizada, como o caso dos médicos, professores e advogados. Os empresários e funcionários públicos também mantiveram o mesmo porcentual e, na categoria "outros", houve apenas uma baixa. Ou seja, mesmo colocando à prova a caracterização profissional por nós elaborada, este pouco difere da definição de Rodrigues (2006) - além, é claro, das especificidades locais.

Quanto ao perfil sócio-profissional dos vereadores, podemos afirmar que a Câmara Municipal de Maringá no período foi de base elitista, ou seja, não houve permeabilidade na inserção de novos integrantes na elite política maringaense. Tal fato comprova-se, pois as maiorias dos vereadores se enquadram nas categorias com maior incidência: professores, advogados, médicos, empresários, funcionalismo público e profissionais liberais, profissões as quais inserimos na elite profissional. 
E, por fim, respondemos a questão: há alguma profissão que combina com a atividade política, isto é, há o favorecimento em uma disputa eleitoral para se tornar vereador em Maringá? Da lista, as três primeiras colocadas foram Medicina, Docência (Professores) e Direito, isto é, a preferência do eleitorado maringaense é por uma classe política com ensino superior e que se formou sob duas vertentes: a tradição do bacharelismo na política brasileira (médicos e advogados) e a docência, no ensino superior ou médio.

\section{CONCLUSÃo}

Ao longo do texto, procuramos expor alguns pontos que apontam para um único caminho: a questão central desta pesquisa, isto é, quem são os componentes da elite legislativa de Maringá? Para tal, percorremos o seguinte itinerário: a identificação da Teoria das Elites enquanto marco teórico, pensando a Câmara Municipal de Maringá como um espaço em que a minoria organizada e articulada - enquanto elite política local, pode comandar uma maioria desorganizada e não coesa; assinalamos a opção pelo método posicional para delimitar nosso universo de pesquisa, ou seja, apenas aqueles que se tornaram vereadores em Maringá posicionalmente no período estudado; e evidenciamos os dados referentes aos vereadores, delineando um perfil do grupo que comandou o legislativo municipal de Maringá desde 1997. Desta trajetória, quais são as considerações finais ou conclusões que podemos aferir?

Primeiramente, salientamos que houve alta rotatividade de lideranças na Câmara Municipal durante as quatro legislaturas (1997-2012). Das 72 vagas disponíveis, apenas 24 não foram ocupadas por novos nomes, isto é, 48 são os vereadores que se elegeram no período, representando assim $66 \%$ do total de cadeiras. Se considerarmos os 9 suplentes que assumiram, o número se eleva para $79 \%$ das vagas, confirmando assim a conclusão do trabalho de Tonella (1991), que salientou a alta mudança de lideranças nos postos de comando na reedição do pluripartidarismo. Logo, podemos questionar: então não há uma elite política em Maringá definida, ou seja, pelo alto índice de alteração das lideranças, é possível dizer que não existe tal elite?

Como exposto, há valores políticos, sociais, econômicos e institucionais para que um indivíduo pertença à elite. Apesar da alta rotatividade de lideranças, é possível afirmar que existem grupos políticos em Maringá e que, apesar das mudanças nas cadeiras da Câmara Municipal, estes atores não deixaram de atuar politicamente. Ou seja, para pertencer à elite política, é necessário possuir bases sociais e psicológicas parecidas (WRIGHT MILLS, 1968, p. 25-) e, posicionalmente, os vereadores 
pesquisados alcançaram tal posto. Esta hipótese se confirma quando observamos a trajetória política dos parlamentares: 32 dos 57 parlamentares ocuparam cargos formais na administração pública, como Deputados Estaduais, Federais, Vice-Prefeito, Vereadores em outras legislaturas, Secretários Municipais, entre outros - sem contabilizar os vínculos institucionais, como presidentes de Associação de Bairros, por exemplo. Enfim, não necessariamente deixar de ser vereador significa deixar de pertencer à elite política.

Ainda assim, afirmamos que os integrantes da Câmara Municipal de Maringá do período não fizeram de seus respectivos mandatos um início para carreira política ascendente (no sentido de se elegerem para Deputado ou Prefeito, por exemplo). Tal ponto contradiz com a afirmação de Dias \& Tonella (1999), que apontam como significativa a parcela de políticos maringaenses que iniciaram carreira no legislativo local enquanto ascensão para outros cargos. Apenas cinco parlamentares obtiveram mandatos de Deputado Estadual e Federal durante os dezesseis anos pesquisados. Por outro lado, ainda permanece a constatação dos autores, no que diz respeito à baixa incidência de Prefeitos de Maringá que começaram a carreira na Câmara Municipal, pois nenhum dos 57 parlamentares foi eleito para a chefia do executivo.

Em relação aos indicadores de escolaridade, os vereadores podem ser considerados como altamente escolarizados, já que dois terços atingiram o ensino superior, concluindo-o ou ainda em curso, superando a parcela da população que cursa ou cursou o ensino superior. Entretanto, o índice de escolaridade dos vereadores não supera os Deputados Estaduais do Paraná entre 1995 e 2002 (CODATO \& GOUVÊA, 2007), pois 89\% possuíam algum curso superior. Quanto à bancada dos cursos na Câmara Municipal de Maringá, os formados em Direito são a maioria, com 21\% dos casos, seguidos dos graduados em Medicina, com 10,6\%. Esta inclinação pelo curso de Direito pode indicar que a atividade legislativa requer um conhecimento de legislação e, pela formação universitária, provavelmente a população optou por especialistas da área. De outro lado, há casos de parlamentares que ainda estavam cursando Direito concomitantemente com o mandato, isto é, a atuação enquanto vereador influenciou na escolha da graduação.

Das quatro legislaturas pesquisadas, a $11^{\text {a }}$ Legislatura (1997-2000) foi a que possuiu o maior número de graduados no ensino superior, com 62,2\% dos parlamentares. Este índice se manteve praticamente em torno de 50\%, para mais ou para menos. Outrossim, o número de parlamentares que possuem apenas o ensino fundamental atualmente é zero, quer dizer, se olharmos para o grau de escolaridade dos parlamentares por legislatura, há uma tendência para a alta escolarização, um claro indicativo de pertencimento a uma elite educacional local - fator que colabora para a 
presença destes na elite política. Portanto, apesar de não superar os índices de escolaridade da Assembleia Legislativa, o eleitor maringaense optou por um legislativo altamente escolarizado e, ao longo dos anos, manteve esta tendência, bem como escolheu representantes com mais tempo de estudo.

Acerca da origem familiar dos vereadores, apenas seis parlamentares já possuíam algum tipo de parentesco com integrantes da história política do município. Tal fato nos permite enfatizar a alta rotatividade de lideranças, bem como confirmar que não há em Maringá uma dominação tradicional (COHN, 2005, p.131), pois crer em "poderes senhoriais há muito existentes" não é um fator preponderante para o maringaense escolher seus representantes. Neste sentido, salientamos que não existem oligarquias políticas no município, pois a liderança exercida pelos chefes do passado não foi transmitida pelos os sucessores das respectivas famílias.

Quanto aos vínculos institucionais, podemos afirmar que $63,2 \%$ dos vereadores pesquisados possuem algum tipo de identificação institucional. Deste porcentual, 24,5\% identifica-se por mais de um vínculo, ou seja, pertence à mais de uma categoria institucional - o que significa dizer que praticamente um quarto dos parlamentares atua intensamente em mais de um campo institucional. Ainda assim, das subcategorias criadas por nós, destacamos a forte atuação nos clubes de serviço e entidades assistenciais, com 27,5\% dos parlamentares optando por este segmento, seguido pelos que atuam em sindicatos e associações classistas (19,7\%), identificação religiosa $(17,7 \%)$ e clubes de futebol (11,7\%). Portanto, os quatro segmentos unidos representam 76,6\% da parcela de vereadores que possuem vínculo institucional, isto é, os parlamentares maringaenses do período identificam-se institucionalmente nestes quatro segmentos - todos tradicionalmente ligados à atuação política: voluntariado e prestação de serviços, militância sindical e classista, representantes de agremiações religiosas e parlamentares ligados à atividade futebolística. Neste sentido, ser vereador implica em possuir uma alta vinculação institucional e, além da atuação dos parlamentares nas instituições anteriormente listadas, salientamos que um quarto destes se insere em mais de um vínculo institucional.

Diante dos vínculos institucionais, questionamos: pertencer a algum destes segmentos é fator que coopera para que o indivíduo torne-se vereador? E mais: vincular-se institucionalmente é uma condição preponderante para o pertencimento à elite política? Não podemos verificar quando estes vereadores começaram a atuar nos segmentos que elencamos. Alguns assumiram posição de liderança antes de vincular-se institucionalmente, outros só participaram de uma instituição após a obtenção do mandato - o que torna difícil responder tal pergunta. Todavia, pertencer a estes segmentos é uma condição importante ao passo que tais parlamentares fazem parte da 
elite política local. Se considerarmos que praticamente dois terços dos vereadores pesquisados vinculam-se institucionalmente, a atuação nestes segmentos nos ajuda a compreender como se comporta a elite política maringaense, quais são seus segmentos institucionais e, porque não, em qual vínculo se apoia eleitoralmente. Ademais, colocamos como hipótese que até mesmo o desempenho das atividades parlamentares deve possuir ligação com este pertencimento institucional - o que não podemos afirmar, já que não possuirmos mais dados, visto não se tratar do objetivo desta pesquisa.

Da trajetória política dos vereadores pesquisados, enfatizamos que $51 \%$ dos parlamentares se elegeram a partir da primeira disputa, o que demonstra tendência para eleição de "novatos" na Câmara Municipal; entretanto, 33,3\% dos parlamentares disputaram duas eleições e $22,9 \%$ três eleições. Como dito, se eleger na primeira disputa não significa que um cidadão comum candidato pela primeira vez, por exemplo, irá se eleger: é necessário estabelecer alguns vínculos para que haja viabilidade eleitoral. Tais números confirmam uma permanência média de oito anos no cenário político local e, após o ingresso na elite política local por intermédio da única disputa, os parlamentares não deixaram de concorrer a uma vaga no legislativo local. Outro ponto relevante é a carreira prévia/posterior dos parlamentares na política maringaense: treze vereadores já haviam cumprido algum mandato na Câmara Municipal antes do período escolhido, bem como quatorze vereadores exerceram as funções de secretário municipal ou cargo de diretoria na prefeitura.

Mensuramos também a faixa etária de ingresso e encerramento da carreira política dos vereadores no período: $38,6 \%$ dos parlamentares iniciaram carreira entre 41 e 50 anos, enquanto que $33,4 \%$ encerram suas carreiras entre os 51 e 60 anos. Se compararmos estes índices com as faixas etárias do eleitorado maringaense, tais valores se aproximam ${ }^{6}: 25,5 \%$ dos eleitores tem entre 45 e 59 anos, 21,9\% tem entre 25 e 34 anos e 19,9\% estão entre os 35 e 44 anos. Assim, a parcela de ingresso e término de carreira política dos vereadores de Maringá se assemelha com a maior concentração da população local.

Sobre a movimentação partidária do período, destacamos as cinco maiores agremiações partidárias do período em relação ao total de parlamentares, comparados com o total de vagas: o PSDB elegeu $18,2 \%$ das cadeiras, o PP preencheu $16,7 \%$ das cadeiras e o PT, PMDB e PTB 11,2\% das vagas. Contudo, apenas PSDB, PT, PMDB e DEM elegeram representantes em todas as legislaturas, consolidando assim as seis maiores siglas partidárias do período (PSDB, PP, PT, PMDB, PTB e DEM). Acerca dos partidos de menor expressão - casos de PRP, PST, PSD, PMN, PC do B e PSB,

\footnotetext{
${ }^{6}$ Segundo dados do TSE (Julho-2010)
} 
constatamos que estas legendas foram de sazonalidade eleitoral, pois apenas elegeram representantes em uma legislatura, não prosperando eleitoralmente.

Dos partidos que elegeram representantes para a Câmara Municipal, PSDB, PP e PT venceram o pleito para o executivo, o que nos indica que os primeiros colocados na disputa do legislativo também elegeram os chefes do executivo. O legislativo local eleito em cada uma das quatro legislaturas acompanhou o prefeito municipal em três oportunidades, na $11^{\mathrm{a}}, 13^{\mathrm{a}}$ e $14^{\mathrm{a}}$ legislaturas. Apenas entre 2001 e 2004, enquanto o PT estava à frente da prefeitura a oposição foi maior na Câmara, sendo 15 vereadores contra 6 situacionistas.

Outro destaque é a questão da fidelidade partidária dos vereadores pesquisados: 52,6\% dos parlamentares não trocaram de partido e 22,9\% dos vereadores mudaram apenas uma vez de partido, isto é, podemos afirmar que há a fidelidade partidária e esta é um fator inerente para que um indivíduo seja eleito vereador, desmistificando a necessidade de implantar medidas para manutenção dos políticos em seus respectivos partidos. Ainda assim, enfatizamos que permanecer no partido é sinal de liderança, não só na agremiação, mas no meio político, demonstrando assim consolidação político-partidária. Em suma: trocar de partido pode significar não se eleger para a vereança.

O levantamento dos dados quanto à origem sócio-profissional dos vereadores nos demonstrou que a base de seleção da elite política legislativa de Maringá é elitista, pois a maioria dos vereadores está classificada profissionalmente em profissionais liberais (médicos, advogados e professores) e funcionalismo público. Ainda assim, 66\% dos parlamentares estão ocupados no mercado de trabalho na mesma profissão cursada no ensino superior ou exercida antes de assumir o mandato na Câmara Municipal. Dos parlamentares que não exercem a mesma ocupação antes de assumir o mandato, destacamos 12 parlamentares que se ocupam da vereança enquanto atividade principal, ou seja, $25 \%$ dos vereadores fazem da função de vereador o principal trabalho para obtenção de renda.

Das profissões e ocupações elencadas dos parlamentares pesquisados, enfatizamos que há inclinação para os profissionais liberais, por 45,7\% o são. Nas profissões que combinam com a atividade parlamentar, professores e advogados lideram o ranking, com 12,3\%, seguidos de médicos, empresários e funcionalismo público, com 10,5\%. Quanto aos títulos profissionais utilizados nas eleições como recurso para obtenção do mandato, destacamos os médicos, policiais e pastores, pois todos os profissionais destas áreas optaram pelos títulos de "doutor", "cabo ou investigador" e "pastor" durante os pleitos. Na contramão, apenas um advogado optou por incluir a expressão “doutor” antes do nome. Disto, concluímos que a classe política 
do período em sua maioria possui algum curso superior, especialmente os voltados para a tradição dos bacharéis (médicos e advogados) e professores.

A radiografia da Câmara Municipal de Maringá entre 1997 e 2012 demonstra um parlamento com alta rotatividade de lideranças, mas que permanecem no cenário político mesmo sem exercer o mandato de vereador; a elite política é altamente escolarizada; não há presença de "oligarquias" na elite legislativa maringaense, pois somente seis foram os casos de relação de parentesco com outros políticos locais; há fortes vínculos institucionais, já que $63,2 \%$ dos vereadores atuam em alguma instituição; o tempo médio de permanência no cenário político local é de 8 a 12 anos, o que confirma a existência de uma elite política consolidada, ratificando a primeira afirmação; a faixa etária de participação política dos vereadores inicia-se, na média, aos 41 anos e se encerra aos 60 anos, confirmando a tendência do eleitorado em eleger representantes da mesma faixa etária da maioria do eleitorado; os três partidos que chefiaram o executivo também obtiveram o mesmo êxito no parlamento - PSDB, PP e PT, somando-se ao PMDB como as maiores agremiações partidárias do período; é alto o índice de fidelidade partidária; e a opção do eleitorado quanto à profissão/ocupação dos vereadores são os profissionais liberais, capitaneados pelos médicos e advogados (tradição do bacharelismo na política brasileira) e dos professores.

\section{REFERÊNCIAS BIBLIOGRÁFICAS}

BRAGA (1998). Quem foi quem na Assembléia Constituinte de 1946: um perfil socioeconômico e regional da Constituinte de 1946. Brasília: Câmara dos Deputados, Coordenação de Publicações.

CÂMARA MUNICIPAL DE MARINGÁ. Base de dados da Câmara Municipal de Maringá. Disponível em: <http://www.cmm.pr.gov.br > Vários acessos.

CODATO, A. PERISSINOTTO, R. Por um retorno à Sociologia das elites. Rev. Sociol. Polít., Curitiba: v. 16, n. 30, p. 7-15, jun. 2008

COHN, Gabriel (Org.) Max Weber - Sociologia. São Paulo: Ática, 2005.

DAHL, Robert. Uma Crítica do modelo de Elite Dirigente. In: Sociologia Política II. Trad. Sylvia Rocha Mendes. Rio de Janeiro: Zahar Editores, 1970.

DIAS, Reginaldo Benedito. TONELLA, Celene. A experiência do Legislativo municipal em Maringá - 1947 - 1998. Maringá: Câmara Municipal de Maringá, 1999.

DIAS, Reginaldo Benedito. Da arte de votar e ser votado: as eleições municipais em Maringá. Maringá: Clichetec, 2008.

GRYNSZPAN, M. A Teoria das Elites e sua Genealogia Consagrada. BIB, Revista Brasileira de Informação em Ciências Sociais., Rio de Janeiro: n. 41., p. 35-83, $1^{0}$ sem. 1996. 
HEINZ, Flavio M. (Org.). Por outra história das elites. Rio de Janeiro: Editora FGV, 2006.

MILLS, C. Wright. A Elite do Poder. Rio de Janeiro: Zahar, 1968.

PERISSINOTTO, R. M.; CODATO, A.; BRAGA, S. S. \& FUKS, M. (orgs). Quem governa? Um estudo das elites políticas no Paraná. Curitiba : UFPR, 2007.

PERISSINOTTO, Renato. As elites políticas: questões de teoria e método. Curitiba: IBPEX, 2009.

PERISSINOTTO, Renato. Notas metodológicas sobre o estudo de elites. Curitiba: Nusp, 2003.

PORTAL GAZETA DO POVO. Gazeta do Povo - site de notícias. Disponível em: $<$ http://www.gazetadopovo.com.br > . Vários acessos.

RODRIGUES, Leôncio Martins. Mudanças na classe política brasileira. São Paulo: Publifolha, 2006.

RODRIGUES, Leôncio Martins. Partidos, ideologia e composição social.: um estudo das bancadas partidárias na Câmara dos Deputados. São Paulo, Edusp, 2002.

TONELLA, Celene. Poder local, partidos e eleições na reedição do pluripartidarismo em 1979/1988: um estudo de caso. 1991. Dissertação (Mestrado) - Universidade Estadual de Campinas, UNICAMP, Campinas, 1991.

TRIBUNAL SUPERIOR ELEITORAL. Base de dados do Tribunal Superior

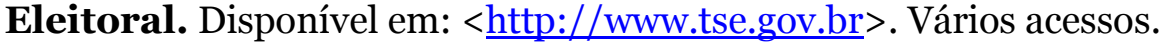

